\title{
The right to refuse treatment is not a right to be killed
}

\author{
Susan L Lowe Department of Philosophy, University of Durham
}

\begin{abstract}
It is widely accepted now that a patient's right to refuse treatment extends to circumstances in which the exercise of that right may lead to the patient's death. However, it is also often effectively assumed, without argument, that this implies a patient's right to request another agent to intervene so as to bring about his or her death, in a way which would render that agent guilty of murder in the absence of such a request. But the right to refuse treatment can, logically, have no such implication, and the mistaken supposition that it does conflates a right to die with a right to be killed. Confusion over this issue is brought out by an examination of conflicting opinion concerning the permissible termination of ventilation for mentally competent patients. A wider lesson may be drawn regarding the need for the ethical assessment of new forms of life-sustaining medical technology.
\end{abstract}

\section{Introduction}

The right of patients to refuse treatment is now widely accepted, recognition of this even being reflected in such government publications as the Patient's Charter. ${ }^{1}$ Although this development is very much to be welcomed, it must be stressed that the existence of such a right by no means implies that there are any circumstances in which patients do or should have a right to be killed. One might have imagined it unnecessary to argue for so obvious a point, but for the fact that the contrary seems to be tacitly assumed by so many contemporary authorities on medical law and medical ethics. I shall focus on the use of ventilators to make my point, and having made it I shall go on to draw some broader lessons concerning the ethical assessment of life-sustaining medical technologies.

\section{The current legal position}

Recognition of a patient's right to refuse treatment

\section{Key words}

Patients' rights; consent; euthanasia; life-sustaining technology; termination of treatment; acts and omissions. may obviously affect both the way in which his or hef condition is treated by the doctor and the prospectis for the patient's recovery, though in many clinicat situations these effects will be unproblematic and uncontroversial. But, of course, very much more dramatic cases can occasionally arise. For, as Lord Keith stated in his judgment in the Anthony Bland case, "a person is completely at liberty to decline tō undergo treatment, even if the result of his doing seb will be that he will die". ${ }^{2}$ Thus, according to current legal opinion, a mentally competent patient, fullÿ understanding the consequences of refusing life-pre serving drugs, may refuse to take them even though his death must be the natural outcome. Likewise patients have a right to refuse to commence life-sus taining kidney dialysis and, indeed, a right to withdraw from such a programme of dialysis, note withstanding the fatal consequences of doing so 3 And surely this state of affairs is indeed preferable to one in which treatment is forced upon unwilling and yet lucid patients who are fully aware of the conse quences of their refusals.

More controversially, however, we find that the courts have recently extended their interpretation of the right to refuse treatment somewhat further andB have ruled that when a mentally competent patien $b$ who is chronically dependent on a ventilato? requests that it be switched off, this request toon should be acceded to in the name of the patient' right to refuse treatment. ${ }^{3}$ However, I shall argues that this is a step too far, because such a request does not amount simply to a refusal of treatment. Rather it is effectively a request to be killed, and as such ought by no means to be acceded to simply in the name of the patient's right to refuse treatment.

Here, of course, it may be queried whether there्? really is any morally or legally significant difference between this sort of case and the ones I mentioned previously. After all, I myself have effectively con $\vec{\Omega}$ ceded, in the case of kidney dialysis patients, that it is not merely wrong to force a patient to initiate life $\frac{0}{0}$ sustaining treatment, but also wrong to force a patient to continue with such treatment, eveng though his death must be the inevitable consequence of his failing to do so. However, I fully accept that forcing a patient to continue with life-sustaining 
treatment is wrong, because it is indeed a violation of the patient's right to refuse treatment. What I deny is that, in the case of the patient chronically dependent on a ventilator, his right to refuse further treatment can legitimately be given effect by requiring the doctors to accede to his request to switch the ventilator off - and I deny this because their doing so would be tantamount to their acceding to the patient's request to be killed. Fortunately, as we shall see, the wrongful forcing of a patient to continue ventilator use is not in fact the sole alternative to refusing to accede to his request to switch it off. But before we look at this solution to the patient's problem, I should first like to query current legal opinion, which seems to find it almost obvious that a patient's request to have his ventilator switched off should be regarded as a legitimate exercise of his right to refuse treatment.

\section{Kennedy's arguments}

A good focus for discussion here is the work of Ian Kennedy, who has analysed in considerable detail the situation of patients who are chronically dependent on ventilators. ${ }^{4}$ In cases where such patients are mentally competent and request termination of treatment, Kennedy claims, in conformity with currently dominant legal opinion, that the correct action is to switch the ventilator off. Significantly, however, in the case of there being no such request, he maintains that switching off the ventilator would actually amount to murder: "There is no doubt that in such a case, given the necessary knowledge and intent, the person turning off the machine would be guilty of murder". ${ }^{5}$ But, evidently, it is quite indefensible to maintain that one and the same action (here, switching off a ventilator supporting the life of a patient) can in one case constitute a morally and legally permissible action while in another it constitutes the crime of murder, depending solely upon whether or not the person whose life is at stake has requested the action to be performed. The law does not regard the consent of the victim of an act of homicide as in any way disqualifying that act from constituting murder. Indeed, as Glanville Williams remarks, the received view in law is that "A person cannot consent to his own death". ${ }^{6}$ Consequently, either Kennedy must be mistaken in his opinion that switching the ventilator off against the patient's wishes would be murder - which seems most implausible - or else he must be mistaken in holding that it is legally permissible to switch the ventilator off when the patient requests this to be done.

Consider, then, Kennedy's reasons for holding that murder is committed if no request for termination has been made by the patient. He uses the analogy of a tightrope-walker whose wire is cut to demonstrate his point. Perhaps, however, an even closer parallel would be that of a deep-sea diver, who we may suppose is connected to an air supply controlled at sea level. If anyone were to disconnect the diver's air supply, against the diver's wishes and in full knowledge that he had no other access to air, then surely that person would indeed be guilty of murder in the event of the diver's dying of asphyxiation. It takes little imagination to see the parallel with the ventilator: switching it off is just like cutting off the diver's air supply, and has the same consequence - the death of the person concerned. Therefore, to switch if off against the patient's wishes is likewise murder. But if we accept this verdict, as I think we should, how can we also agree with Kennedy that if the patient requests the ventilator to be switched off, the doctor ought to comply? After all, if the diver were likewise in verbal contact with the ship and requested the air supply to be cut - perhaps because he couldn't face some difficult situation awaiting him on the surface - would the fact of this request having been made constitute any sort of defence on the part of someone who complied with it by cutting the diver's air supply? Surely not. This would still be murder, however much sympathy we might feel for the people involved.

At this point it may be appropriate to cite the classical legal definition of murder, which is that of Coke: "Murder is when a man of sound memory, and of the age of discretion, unlawfully killeth within any county of the realm any reasonable creature in rerum natura under the King's peace, with malice aforethought, either expressed by the party or implied by law, so as the party wounded, or hurt, etc. die of the wound or hurt, etc., within a year and a day after the same". ${ }^{7}$ However, some clarification is essential here. "Malice aforethought" is a technical legal term and as such has a specific meaning quite different from that understood in common parlance. The phrase, to quote C S Kenny, "is a mere arbitrary symbol . ..., for the 'malice' may have in it nothing really malicious; and need never be really 'aforethought' ". ${ }^{7}$ For example, killing a suffering child out of a motive of compassion is still held to be "malicious" and it is sufficient that the intention to kill be formed only momentarily prior to the fatal blow. Neither ill-will nor premeditation is necessary. I mention this lest anyone should mistakenly think that good will felt for the distressed diver by the person cutting his air supply would have any bearing on a verdict of murder against that person.

\section{Right to refuse}

With this clarification in mind, let us return to Kennedy. To be fair, Kennedy's arguments are quite complex and do not merely appeal to the fact that a request, as such, has been made. Essential to his position is his claim that just as a patient has a right to withdraw from a programme of kidney dialysis, that is, to refuse further treatment, so the ventilator-dependent patient also has a right to refuse further treatment: "There should be no 
difference in principle between the patient diagnosed as having irreparable kidney failure who refuses to submit to dialysis on an artificial kidney or who refuses to continue such treatment and the refusal of the polio victim on the respirator". 8 However, although one may sympathise with the spirit of this remark, it seems clear that as things stand at present there is in fact a very important difference between the two sorts of situation described by Kennedy, for the reason which I have just stated. Requesting that one's ventilator be switched off is not equivalent either to refusing life-preserving drugs or to refusing to engage in or continue with dialysis - nor, indeed, is it even equivalent to refusing to be attached to a ventilator in the first place. The reason for the difference is that the former is a request that someone should intervene to bring about the patient's death, in a way which would clearly constitute murder in the absence of such a request - and, as we have seen, the existence or non-existence of such a request is simply irrelevant, in law, to the status of this action as murder. Thus, while I would agree that in the other cases described by Kennedy a patient is indeed simply exercising his right to refuse treatment, I would none the less insist that in the ventilator case the patient is doing more than this - he is requesting someone else to perform a legally and morally impermissible action, namely, to kill him. The right to refuse treatment may entail a right to die, but it does not entail a right to be killed.

In order to forestall premature criticism, I should acknowledge here that it has been argued - notably in the Bland case - that switching off a ventilator is really an "omission", and that this might be taken to imply that even when such a switching off leads to the patient's death it cannot be regarded as amounting to killing. In fact, however, as we shall see more fully later, the "acts" and "omissions" distinction - which is fraught with difficulty in any case - is irrelevant to the real problem now at issue. For the moment I would just point out that there is no inconsistency in saying that one person may kill another by "omitting" to do something: for instance, one may certainly kill another person by omitting to remove one's hands from that person's throat!

\section{Voluntary active euthanasia}

Let us, however, examine a little further Kennedy's arguments for the permissibility of compliance with a request of the kind in question (a request to be killed). It should be emphasised that Kennedy himself denies the permissibility of this in the imagined case of a mentally competent and wellinformed patient requesting to be stabbed to death. So he denies its permissibility in the case of stabbing but not in the case of switching off a ventilator. Compliance in the former case Kennedy regards as voluntary active euthanasia, claiming that it amount to "homicide". 9 And he is surely right. One may wepp. ask, then, how he can square this with his other claim that switching off a ventilator in compliances with the patient's request is a morally and legally permissible action when the patient is mentally $\operatorname{com} \frac{\overline{\bar{s}}}{\text {. }}$ petent and fully informed. I consider that Kennedy'扂 attempts to render these two claims consistent are manifestly inadequate.

That the request in a ventilator case is a "compar $\overrightarrow{\overline{0}}$ atively rare phenomenon"9 is surely not at all to the point. (A request to be stabbed to death would notw I think, be a particularly common phenomeno either!) As for Kennedy's suggestion that "th criminal law can respond to it as a tolerable and jusit tifiable exception to basic criminal law rules develes oped long before respirators ever existed", 9 this if blatantly ad hoc and question-begging. That "stabbing is at least potentially more open to abuse", ${ }^{9}$ and that switching off a ventilator "lets other factors intercede and thrusts the last decision back to the patient who can still (in theory, at least $\phi$ change his mind"9 are, I would urge, equally feeble reasons for purporting to discern a morally an£ legally relevant difference between the two casesThus I find all of Kennedy's attempts to justify hie position and render it consistent entirely unsatis factory.

\section{The irrelevance of the acts and omissions} distinction

Moving on from Kennedy, now, I want next to consider another common line of argument purport ing to justify the switching off of ventilators in the name of the patient's right to refuse treatment - one which appeals to the notorious distinction between acts and omissions. A careless reader might have imagined that I myself was appealing to this very dis tinction a little earlier in order to argue for the contrary position. That is to say, it might have been imagined that I was arguing as follows: switching off ventilator is to be viewed as an active intervention possibly leading to the patient's death - and as suclP morally and legally impermissible because in than event it would amount to killing rather than letting die - whereas, by contrast, if a ventilator is not switche on, with the consequence that a patient dies, then n\& accusation of killing can properly be levelled agains居 anyone. The trouble with such an argument is simply cannot be assumed that everyone will accept aso uncontroversial the claim that switching off a ventila tor constitutes an "act" rather than an "omission" Indeed, the contrary line of argument - now appar. ently in favour amongst many legal experts - is pre $\frac{0}{\sigma}$ cisely that switching off a ventilator should in fact be viewed as an omission, and consequently that whet this happens and a patient dies as a result, an accusd tion of killing can no more be properly levelled agains anyone than if the death had occurred because the 
ventilator had not been switched on in the first place. Thus Lord Browne-Wilkinson has argued as follows in the Bland case: " $[E]$ ssentially what is being done is to omit ... to ventilate: [and] ... the switching off of a ventilator [is] merely [an] incident of that omission". ${ }^{10}$ (He cites in support of this view Williams ${ }^{11}$ and Skegg. ${ }^{12}$ ) In reality, however, my own argument does not appeal to the thoroughly dubious distinction between acts and omissions, and the contrary line of argument just outlined is fatally flawed precisely because it does make such an appeal, when in fact the distinction in question is simply irrelevant to the issue in hand.

That this is so is plain to see, if we just retrace once more my earlier train of reasoning. Suppose a ventilator patient makes it known that he certainly does not want the ventilator to be switched off. If someone were, none the less, to switch it off, fully aware of the fatal consequences for the patient, it is surely clear - as we saw before - that such a person would be guilty of murder. Now, as we also saw before, it is equally clear that, in law, murder is murder quite irrespective of the victim's wishes, which make no difference at all to the status of the offence - and this holds true however one may choose to classify the perpetrator's behaviour in terms of the (highly controversial) "acts" and "omissions" distinction. Whether one classifies switching off the ventilator as technically being an "act" or an "omission" - and debate over this could go on for ever - the fact remains that switching it off against the patient's wishes constitutes murder, and murder is murder irrespective of the wishes of the person whose death is at issue. As Lord Mustill remarked in the Anthony Bland case: "So far as I am aware no satisfactory reason has ever been advanced for suggesting that it makes the least difference in law, ... . if the patient consents to or indeed urges the ending of his life by active means". ${ }^{13}$

\section{Beside the point}

I conclude, then, that the issue of whether or not switching off a ventilator with fatal consequences for the patient constitutes an "act" or an "omission" is simply beside the point when it comes to deciding whether or not doing so is permissible in law when a patient has requested it to be done. If - as is clearly the case - it is not permissible in the absence of such a request, then neither is it permissible when such a request has been made. The fact that the courts themselves have on occasion evidently considered the acts and omissions distinction to be relevant to this sort of question simply testifies to confusion on the part of the legal experts concerned. In illustration of this confusion, it may be noted that Lord Mustill himself, in discussing the difference between terminating artificial feeding (which he parallels with ventilator use) and mercy killing (such as stabbing a patient who has requested it) remarks that "The conclusion that the declarations can be upheld depends crucially on a distinction drawn by the criminal law between acts and omissions", but then lamely adds that "The acute unease which I feel about adopting this way . . . is I believe due . . . to the sensation that . . . the ethical status of the two courses of action is for all relevant purposes indistinguishable". ${ }^{14}$

\section{An alternative solution to the problem}

But let us now try to get at the real root of the difficulty concerning ventilator use and its termination, given that the acts and omissions distinction is just a red herring in this context (as indeed Ian Kennedy recognises, ${ }^{9}$ unlike many who approach the problem from a legal background). I acknowledged earlier that it is wrong to force a patient to continue to receive treatment against his will, even if the cessation of treatment must result in his death. So how can I also maintain that it is wrong to switch off a ventilator at the patient's request and, indeed, that doing so amounts to murder? Well, I think I have sufficiently explained why we must view this as murder, given that we would regard it as murder if it were done contrary to the patient's wishes. So what I need to explain is how, consistently with this, I can think it right and feasible to comply with the patient's request that he should not have to continue to receive ventilator treatment against his will. My view is that the key to the difficulty lies with the mode of operation of the ventilator itself. It is the fact that the ventilator has to be switched off by someone that leads to the problem. So why not use a ventilator which is programmed to switch itself off after a designated period of hours or days, thus making it necessary for a doctor or nurse to switch it on in order to continue treatment? A doctor would not then be put into the position of having to decide whether or not to switch it off. (Obviously, safeguards would need to be incorporated to ensure that medical staff did not forget to switch the ventilator on when required and that the procedure could be carried out, if necessary, without any deleterious interruption of treatment.) The significant feature of a ventilator of this alternative design is that the doctors would, every day or so, be placed in the same practical and ethical situation as they were when making the original judgment to initiate treatment, and this only demands a decision on the doctors' part as to whether or not to switch the ventilator on. For, it seems clear, a decision not to switch the ventilator on in the first place, made conscientiously in the light of the doctors' prognosis, would never be regarded as making them liable to a charge of murder if the patient were to die as a consequence. 
A similar idea has been mentioned before by, amongst others, Glanville Williams ${ }^{11}$ and Peter Skegg ${ }^{15}$ - both of whom were, interestingly enough, referred to by Lord Browne-Wilkinson in the Bland case. ${ }^{10}$ However, none of these individuals seems to recognise the true significance of the proposal, merely suggesting it as a curious afterthought or side-issue - perhaps because they can hardly believe that so simple a solution is to hand. This is particularly striking in the case of Skegg, who seems implicitly to concede that the proposal does provide the solution to the whole difficulty without acknowledging that this renders unnecessary much if not all of his preceding twenty-page discussion! His concluding paragraph ends as follows: "In the almost unthinkable event of a judge directing the jury that the doctor was guilty of murder in such circumstances ... [ $t$ ] he problem could ... be overcome for the future by equipping ventilators with a device that would automatically switch off a ventilator after twelve hours if it were not reset for another twelve ... and there would be no need for a doctor to do anything to terminate artificial ventilation". ${ }^{16}$

Thus, it seems, following this simple technical modification, we would genuinely be presented with a situation comparable with that of kidney dialysis, just as Kennedy erroneously thinks we are with existing ventilator regimes. Similarly, we would then have a genuine parallel with the use of life-preserving drugs. Under this new regime, the patient would be able to refuse treatment either by refusing to be attached to the ventilator in the first place or else by refusing to have it switched on again after a prescribed period. Hence no one need be granted the right to be killed in order to enable them to exercise their right to refuse treatment in such situations. The ventilator could switch itself off just as a session of dialysis comes to an end and just as a life-preserving drug ceases to have its effect. In all these cases, now, the doctor would need the patient's agreement in order to continue medical treatment.

\section{Conclusion}

If this view of the matter is accepted, then perhaps a wider lesson may be drawn. This is that types of medical equipment, quite as much as types of drug $\overrightarrow{2}$. need to be subjected to scrutiny to ensure that their mode of operation is morally acceptable. Had this been done in the case of ventilators, then perhaps the? problem that we have been discussing would neve? have arisen and the courts would not now be in the absurd position of having to concede, in effect, a right to be murdered in order to enable certain patients to exercise their right to refuse life-sustaining treatment Making it a requirement for members of the medicat profession to kill their patients in certain circumstances must inevitably create anxiety and distrus $\vec{w}$ amongst the old and the vulnerable, even if every? feasible safeguard against abuse is adopted. Surely i is better to avoid such a situation if at all possiblen consistently with according patients the right tow refuse treatment which contemporary public opinion demands. Fortunately, we have seen that, at least in one important class of cases, this is indeed possible and can be achieved at very little cost.

Susan Lowe, BA, is Tutor in Philosophy in the Department of Philosophy, the University of Durham. $\overrightarrow{0}$

\section{References}

1 Anonymous. Government response to euthanasia report. Bulletin of Medical Ethics 1994; 97: 8-11.

2 Kennedy I, Grubb A. Medical law [2nd ed]. London Butterworths, 1994: 1270.

3 See reference 2: 1209, 1221, 1270-1.

4 Kennedy I. Switching off life support machines: the legal implications. Criminal Law Review 1977; 442-52?

5 See reference 4: 452 .

6 Williams G. Textbook of criminal law [2nd ed]. London:Stevens, 1983: 579-80.

7 Smith JC, Hogan B. Criminal law [5th ed]. London: Butterworths, 1983: 274

8 See reference $4: 450$.

9 See reference 4: 449 .

10 See reference 2: 1209

11 See reference 6: 282 .

12 Skegg PDG. Law, ethics and medicine. Oxford: Oxford University Press, 1985: 169-71.

13 See reference 2: 1305.

14 See reference 2: 1307-8.

15 See reference 12: 170.

16 See reference 12: 181 